\title{
Direções para a espiritualidade ecumênica: um olhar de um não católico sobre Unitatis Redintegratio
}

\author{
Directions for the ecumenical spirituality: \\ a view of a non-Catholic on Unitatis Redintegratio
}

Gerson Lourenço Pereira

\section{Resumo}

Celebrar os 50 anos do fim do Concílio Vaticano II implica também em rememorar as contribuições e direcionamentos que Unitatis Redintegratio trouxe como brisa arejadora sobre a espiritualidade ecumênica. Assim, o presente artigo busca lançar o olhar de um metodista cuja práxis conjunta, diálogo, convivência fraterna e experiências orantes com católicos o permitem refletir a respeito dessas contribuições.

Palavras-chave: Espiritualidade ecumênica. Unitatis Redintegratio. Ecumenismo. Metodismo.

\begin{abstract}
To celebrate the 50th anniversary of the Second Vatican Council order also implies remembering the contributions and directions that Unitatis Redintegratio brought as a breeze on ecumenical spirituality. Thus, this article seeks to throw the gaze of a Methodist whose collective praxis, dialogue, fraternal coexistence and prayerful experiences with the Catholic allow reflecting on these contributions.
\end{abstract}

Keywords: Ecumenical spirituality. Unitatis Redintegratio. Ecumenism. Methodism. 


\section{Introdução}

Duas observações se mostram pertinentes ao tomarmos em consideração os 50 anos do término do Concílio Vaticano II (1965). A primeira está contida na afirmação de que tal evento, sob a inspiração do Espírito Santo, representou um marco histórico com profundo impacto não apenas em particular para a Igreja Católica Romana, mas ao cristianismo ao redor do mundo em geral.

A segunda observação a ser feita corresponde, em termos específicos, ao diálogo ecumênico com o protestantismo propiciado ao longo da sua realização, assim como após a promulgação das suas constituições, decretos e declarações. Essa porta aberta permite que hoje uma acessível e sensível relação entre os dois universos eclesiásticos ocorra, tanto nos níveis institucionais como eclesiais.

Mesmo gozando de indubitável relevância para a unidade entre as igrejas, no campo do diálogo interinstitucional e doutrinário as proposições conciliares são passíveis de incorrer nos riscos da incompreensão, da distorção das suas intencionalidades, da negação e, não raro, do repúdio. Claros são os movimentos possíveis nesse campo de diálogo: do avanço ou do retrocesso.

Contudo, quando se parte para o caminho do diálogo no cerne das experiências eclesiais, requisita-se outra linguagem, a do coração, da experiência. Essa linguagem tem a ver com o cultivo e partilha da espiritualidade. O movimento que marca tal experiência espiritual não é o avanço ou o retrocesso. O movimento marcante da espiritualidade é o envolvimento! Aliás, quando há avanços no diálogo institucional e doutrinário, é sinal de experiências com a dinâmica do envolvimento fruto da ação do Espírito.

Podendo afirmar que o Vaticano II contribuiu com significativos avanços institucionais e doutrinários para o ecumenismo, é verdadeira também sua contribuição legada à espiritualidade cristã necessária para o diálogo com outros referenciais cristãos. Nesse sentido se destaca o Decreto Unitatis Redintegratio sobre o Ecumenismo, aprovado na sessão de 21 de novembro de $1961 .{ }^{1}$

Este trabalho busca destacar as direções para o desenvolvimento da espiritualidade ecumênica contidas no documento Unitatis Redintegratio, partindo do olhar específico de um metodista. Um olhar inquieto e preocupado com os rumos do atual diálogo particular entre as igrejas Católica Romana e Metodista no Brasil; porém, esperançoso em relação às possibilidades de envolvimento pelas experiências pneumatológicas vivenciadas na sua própria caminhada.

${ }^{1}$ HORTAL, Jesús. E haverá um só rebanho. História, doutrina e prática católica do Ecumenismo. 2a ed. São Paulo: Loyola, 199, p. 212. 
Almejando guiar-se por tais direções, o presente texto apresentará inicialmente as características da espiritualidade ecumênica; em seguida, explicitará as inspirações lançadas por Unitatis sobre tal espiritualidade; e finalmente, destacará as pontes de diálogo, iluminadas pelo Decreto entre as igrejas Católica e Metodista, exemplificando as possibilidades da ação do Espírito no fortalecimento da comunhão do Povo de Deus.

\section{Marcas da Espiritualidade Ecumênica}

O que significa ser ecumênico? Quando uma pergunta de cunho ontológico, tal como essa, é lançada, sobrevém provável inquietação pela busca de respostas, pois desequilibra uma ordem constitutiva já estabelecida, ameaçando desconstruí-la. Redireciona a atenção para novos sentidos, novas perspectivas.

Corresponder à pergunta proposta implica em autoidentificão com princípios norteadores da fé, exprimindo-os de maneira concreta, manifestando-os por meio de uma forma de espiritualidade que traz consigo algumas peculiaridades. Ser ecumênico é nutrir sentimentos e observar atitudes inspiradas por uma espiritualidade ecumênica.

Leonardo Boff, ao refletir a respeito da tênue distinção entre mística e espiritualidade, assevera ser a primeira dimensão antropológico-teológica a experiência sensorial com o Mistério, nomeado pela tradição judaico-cristã de Deus. É mais que pensar sobre seu Ser, do que formular doutrinariamente postulados que $\mathrm{O}$ afirmem. É senti-Lo no corpo, na alma, no espírito. ${ }^{2}$

Numa definição, Boff esclarece que:

Espiritualidade é a transformação que esta mística produz nas pessoas na forma de olhar a vida, no jeito de encarar os problemas e de encontrar soluções. Uma pessoa espiritualizada é aquela que sempre está atenta e se pergunta: o que Deus está dizendo com isso ou aquilo que estou vivendo? Que lição Ele quer transmitir? Que chance de crescimento está me proporcionando? ${ }^{3}$

Sendo encantado pelo Mistério, o ser humano busca nutrir seus anseios de transcendência, superando a finitude de sua existência. Esse encantamento

\footnotetext{
${ }^{2}$ BETTO, Frei; BOFF, Leonardo. Mistica e Espiritualidade. $6{ }^{\mathrm{a}}$ ed. Rio de Janeiro: Garamond, 2005, p. 27.

${ }^{3}$ BETTO, Frei; BOFF, Leonardo. Mistica e Espiritualidade, p. 28.
} 
que deslumbra e fascina, motiva a busca pelos traços da presença divina no coloquial, na trivialidade da vida, tanto quanto nos espaços simbólicos de experiência com essa presença.

Espiritualidade ecumênica é, pois, a expressão da procura da presença misteriosa de Deus nas relações comuniais, ou koinônicas, que extrapolam a formalidade de uma reunião, ou até mesmo a estética oportuna para uma dita celebração litúrgica. Aqui reside um desafio. A maior dificuldade, por mais paradoxal que pareça, é desenvolver uma espiritualidade ecumênica, mais do que realizar um encontro ecumênico.

Ribeiro e Cunha, refletindo a respeito de tal expressão da espiritualidade cristã, destacam a Bíblia como a fonte que anima a pessoa cristã para a tarefa do diálogo e comunhão com outros referenciais de fé.

A Bíblia, quando lida como 'espelho' da fé - e não como manual dogmático - interpela fundamentalmente a vida humana. Se ela é vista como elemento simbólico profundamente arraigado na experiência humana, e não como manual histórico de mero conhecimento, cada pessoa e cada grupo, ao adentrarem em sua leitura (ou escuta), se colocam também lá dentro. Com isso, nos fazemos novos Adão e Eva, novos Moisés, ainda que sem a mesma pujança de Jesus, mas com condições mínimas e não isentas de contradições, para rever a vida, modificar rumos, perdoar e sermos misericordiosos. ${ }^{4}$

Praticar a espiritualidade ecumênica é sentir-se convidado ao exercício da compaixão e longanimidade. É trilhar um "caminho das pedras" fixado em aspectos comuns dentro da diversidade de igrejas e pluralidade religiosa. Um caminho que Santa Teresa ajuda a trilhar calcado na oração, na humildade e no perdão ${ }^{5}$. Que o legado wesleyano convida a lembrar na declaração: "Se o teu coração é igual ao meu, dá-me a tua mão". ${ }^{6}$ Caminho proposto de cura plenas do corpo místico de Cristo, de restauração koinônica. ${ }^{7}$

\footnotetext{
${ }^{4}$ RIBEIRO, Cláudio; CUNHA, Magali. O Rosto Ecumênico de Deus: reflexões sobre ecumenismo e paz. São Paulo: Fonte Editorial, 2013, p. 269.

${ }^{5}$ PEREIRA, Gerson Lourenço. "Luzes da espiritualidade teresiana para o diálogo ecumênico e inter-religioso atual”. In: PEDROSA PÁDUA, Lúcia; CAMPOS, Mônica Baptista (Orgs.). Santa Teresa: mística para o nosso tempo. Rio de Janeiro: PUC-Rio/Reflexão, 2011, pp. 203-225.

${ }^{6}$ WESLEY, Jonh. O Espírito Católico in: John Wesley. Sermões, Edição Editeo - versão digital. Apud: VVAA. Sermões de Wesley: Texto em inglês com duas versões em português. São Bernardo do Campo, SP: Editeo, 2006. CD-Rom, Sermão 39.

${ }^{7}$ NOLAN, Albert. Jesus hoje: uma espiritualidade de liberdade radical. São Paulo: Paulinas, 2008, pp. 119-133.
} 
Trata-se da espiritualidade do encontro, tal como a experiência feita pela mulher samaritana com Jesus de Nazaré, conforme o relato joanino (cf. Jo 4,142). Nenhum diálogo de cunho doutrinário, nenhuma divergência teológicodogmática foi imposta com condição para a aproximação. A despeito dos senões étnicos, sociais, culturais e religiosos, a motivação para o encontro se deu a partir de uma necessidade concreta: a sede! "Dá-me desta água". Dali para frente foram requisitados os imperativos do perdão, da mudança (conversão do) de coração, da humildade, da caridade. ${ }^{8}$

Essas são as marcas da espiritualidade ecumênica, cuja sede de Deus se sacia na fonte da Sagrada Escritura. É a espiritualidade que semeia a comunhão. Que, segundo o Cardeal Walter Kasper', se expressa nas súplicas pela unidade dos cristãos inspiradas na Oração Sacerdotal de Jesus (cf. Jo 17,21). Como uma fonte inspiradora, o Decreto Unitatis Redintegratio é ao mesmo tempo guia e objeto da ação do Espírito para o fortalecimento da comunhão cristã.

\section{Direções de Unitatis Redintegratio para a Espiritualidade Ecumênica}

Yves Congar, ocupado em apontar para a Pneumatologia do Concílio Vaticano II, constata o forte acento Cristológico contido nas deliberações e documentos. Entretanto, refletindo, destaca:

Ora, o Espírito não é pura força impessoal: o Símbolo o classifica como Senhor. Mas continua sendo o Espírito de Cristo. O concílio retoma a ideia neotestamentária que encontramos em Irineu, da função eclesial de santificação como participação na unção de Cristo pelo Espírito. ${ }^{10}$

Congar também reconheceu como uma grande reentrada do Espírito Santo na eclesiologia do Vaticano II a menção, inserção e ponderação acerca dos carismas. Nesse sentido, em matéria de ecumenismo, citando o Decreto Unitatis Redintegratio, recordou a profissão conciliar de não colocar barreira às futuras inspirações do Espírito face ao desafio da unidade entre os cristãos. ${ }^{11}$

\footnotetext{
${ }^{8}$ CONIC e CLAI. Diversidade e Comunhão. Um convite ao ecumenismo. 4 a ed. São Leopoldo: Sinodal; São Paulo: Paulinas, 2004, pp. 13-17.

${ }^{9}$ KASPER, Cardeal Walter. Guia para uma espiritualidade ecumênica. São Paulo: Paulinas, 2007 (Coleção oikoumene), p. 9.

${ }^{10}$ CONGAR, Yves. Revelação e experiência do Espirito. São Paulo: Paulinas, 2005 (Coleçãoo creio do Espírito Santo, v. 1), p. 219.

${ }^{11}$ CONGAR, Yves. Revelação e experiência do Espírito, pp. 222-223.
} 
Sem sombras de dúvida, nas palavras de Elias Wolff ${ }^{12}$, o Decreto Unitatis Redintegratio é uma das maiores expressões conciliares sobre o ecumenismo, levada pelos doces aromas do Espírito, sendo fonte e guia para a espiritualidade ecumênica. Estabelecendo as bases doutrinárias e pastorais para a prática ecumênica da Igreja Católica, divide-se em três capítulos: $1^{\circ}$ - Os princípios católicos do ecumenismo (UR 2-4); $2^{\circ}$ - A prática do ecumenismo (UR 5-12); e $3^{\circ}$ - As igrejas e comunidades eclesiais separadas da Sé Apostólica Romana (UR 13-23). ${ }^{13}$

Salvo algumas críticas na perspectiva protestante ${ }^{14}$, o presente texto aterá para o que propriamente o Decreto assinala como fundamental para o tema proposto. Dessa forma podem ser captados os influxos pneumatológicos inspiradores para a unidade eclesial ao longo do documento.

Como ponto de partida está o reconhecimento do empenho do movimento ecumênico como "sopro da graça do Espírito Santo", exortando os fiéis católicos ao envolvimento e participação (UR 4). Assim, Unitatis Redintegratio lembra que toda iniciativa em prol da unidade encontra sua força motivadora e animadora no Espírito, antes de qualquer motivação política ou institucional. Ademais, seguem outras direções apontadas para a espiritualidade ecumênica.

Objetivamente, Unitatis Redintegratio refere-se ao ecumenismo espiritual como forma de cooperação prática entre as igrejas cristãs. Sendo, portanto, a primeira direção o apelo à Conversão do coração e à Oração comum.

Esta conversão do coração e santidade de vida, juntamente com as preces particulares e públicas pela unidade dos cristãos, devem ser tidas como a alma de todo o movimento ecumênico e, com razão, podem ser chamadas de ecumenismo espiritual. (UR 8)

\footnotetext{
${ }^{12}$ WOLFF, Elias. "O ecumenismo no horizonte do Concílio Vaticano II". Atualidade Teológica 39 (2011), pp. 403-428.

${ }^{13}$ COMPÊNDIO DO VATICANO II. Constituições, Decretos, Declarações. $23^{\mathrm{a}}$ ed. Petrópolis: Vozes, 1994, pp. 307-332.

${ }^{14} \mathrm{O}$ teólogo luterano Gottifried Brakemaeier menciona que, apesar do efeito extraordinário que o Vaticano II provocou no diálogo ecumênico, expõe certa ambiguidade em alguns textos ao não afirmar expressamente que a Igreja de Cristo "subsiste" em outras igrejas, por referir-se apenas às Igrejas Ortodoxas como "igrejas irmãs" e falar em "reintegração da unidade" lembrando o objetivo da reincorporação das demais igrejas na instituição católico-romana. In: BRAKEMEIER, Gottfried. "Preservando a unidade do espírito no vínculo da paz": um curso de ecumenismo. São Paulo: ASTE, 2004, pp. 52-53.
} 
Caminhar rumo à reintegração da unidade requer o despertamento da consciência através do reconhecimento das faltas cometidas que abriram feridas. Isso operado por meio da oração intercessória em favor da unidade que, em outras palavras, tem a ver com a cura do corpo eclesial. Esse despertar do coração corresponde a um dos imperativos que alimentam a espiritualidade ecumênica. Desse despertamento advêm a humildade e a inspiração para a prática do perdão.

Unitatis Redintegratio também alimenta a espiritualidade ecumênica incentivando o estudo da Sagrada Escritura como mediação para a promoção da unidade, fundamentalmente com as comunidades separadas no Ocidente.

Invocando o Espírito Santo, nas próprias Sagradas Escrituras, procuram a Deus, que lhes fala em Cristo prenunciado pelos profetas, Verbo de Deus por nós encarnado. Nelas contemplam a vida de Cristo e aquilo que o Divino Mestre ensinou e realizou para a salvação dos homens, sobretudo os mistérios de Sua morte e ressurreição... No próprio diálogo as Sagradas Letras são exímios instrumentos na poderosa mão de Deus para a consecução daquela unidade que o Salvador apresenta a todos os homens. (UR 21)

Recordando a Bíblia como fonte primordial para fortalecimento da espiritualidade ecumênica, o direcionamento do Decreto presta significativa orientação ressaltando o valor das Escrituras para o estudo partilhado fomentador da unidade. Sem ocultar as divergências hermenêuticas, Unitatis Redintegratio busca um olhar sobre o que sustenta a comunhão. Ao redor da Palavra as comunidades se integram e estabelecem projetos comuns.

Pela forma como se propõe o ecumenismo espiritual, Unitatis Redintegratio celebra como finalidade última e primeira o que Dietrich Bonhoeffer concebeu por "comunhão espiritual" na qual se "vive o radiante amor do serviço fraternal, o ágape". Onde "submissão humilde entre os irmãos", "reina a Palavra de Deus" e "todo poder, honra e domínio estão entregues ao Espírito Santo". ${ }^{15}$

Animando as possíveis relações intereclesiais e intereclesiásticas, as luzes lançadas pelo Decreto auxiliaram no clareamento dos rumos do diálogo entre metodistas e católicos. A espiritualidade alimentada tem envolvido os vínculos institucionais de tal sorte que muitos foram os avanços. Porém,

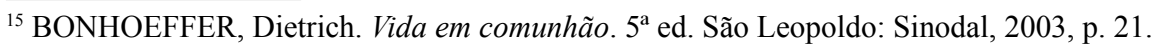


no que pese o otimismo que se deve manter diante da causa ecumênica, a dinâmica do retrocesso no campo do diálogo institucional doutrinário também se constitui numa infeliz marca dessa trajetória.

\section{Pontes para o Diálogo Ecumênico: Católicos e Metodistas}

Sendo a última parte desta reflexão, serão abordados brevemente os principais aspectos da história comunial entre católicos e metodistas como influxo direto das definições conciliares, fundamentalmente contidas no referido Decreto Unitatis Reditegratio. Tal relacionamento bilateral exemplifica concretamente a possibilidade da semeadura da comunhão como expressão da espiritualidade ecumênica.

Reafirmando a recorrência do risco de retrocessos no campo do diálogo institucional doutrinário, as experiências relacionais da Igreja Católica com a Igreja Metodista se revelam constantes, contínuas e enriquecedoras ao longo dos últimos 50 anos. Sendo correto afirmar a abertura ecumênica católica como algo recente, resultante dos ventos liberalizantes do Vaticano II, da mesma forma não é equivocado chamar a atenção para a intrínseca relação e intensa participação metodista nesse processo de abertura.

O primeiro destaque a ser feito, nessa relação, é a participação do teólogo metodista argentino José Míguez Bonino como um dos observadores metodistas do Concílio ${ }^{16}$. A propósito, Bonino foi o único protestante latinoamericano encarregado por tal representação pelo Conselho Mundial Metodista, uma vez considerada sua atuação e reflexões a respeito do diálogo ecumênico e na defesa dos direitos humanos.

Bonino foi um influente interlocutor no diálogo com a Igreja Católica Romana desde antes do Vaticano II, assim como em momentos ulteriores ao Concílio. Como resultado de sua intensa participação publicou, em 1967, as impressões e reflexões sobre as implicações para o protestantismo latinoamericano do referido Sínodo, no livro "Concílio Aberto: uma interpretação protestante do Concílio Vaticano II" ${ }^{17}$.

\footnotetext{
${ }^{16}$ Para a ocasião do Vaticano II foi designado um grupo de 16 observadores, com sólida e qualificada formação teológica, além de vívidas experiências na caminhada ecumênica no âmbito mundial. Embora de variadas nacionalidades, destaca-se o argentino José Míguez Bonino por sua atuação e reflexão posteriores.

${ }^{17}$ BONINO, José Míguez. Concilio Abierto. Una iterpretación protestante del Concilio Vaticano II. Buenos Aires: La Aurora, 1967. (Não disponível em língua portuguesa).
} 
Além de evidenciar a importância das deliberações conciliares para todo o cristianismo mundial, Bonino abriu nesse escrito um panorama para discussões de cunho eclesiológico com o protestantismo, partindo das reflexões em torno da tradição, escritura e teologia católica. De uma maneira crítica, mas ao mesmo tempo otimista, enfatizou com certa dose de entusiasmo um futuro promissor diante dos desafios de atualização e renovação da Igreja Católica Romana.

Seria injusto aqui esgotar a exposição do leque de contribuições do trabalho de José Míguez Bonino na interlocução para o diálogo ecumênico, especialmente entre os metodistas. Falecido em 30 de junho de 2012, aos 88 anos, é digno aqui o registro do que sua pessoa representa para a relação entre católicos e metodistas na América Latina, para o ecumenismo neste Continente e para o Movimento Ecumênico Mundial, a saber: alguém profundamente inspirado, portador de uma espiritualidade engajada na causa da reintegração da unidade entre os cristãos. ${ }^{18}$

Outra referência à relação do metodismo no processo de abertura para o diálogo ecumênico, no campo institucional, é a experiência da constituição da Comissão Mista da Igreja Católica Romana e do Conselho Mundial Metodista, como outras experiências católicas de diálogo (bilaterais e multilaterais) com outras tradições e confissões eclesiásticas ao longo do período pós-conciliar. ${ }^{19}$

Afora a participação de José Míguez Bonino como observador e posterior publicação das suas impressões sobre o Vaticano II, as iniciativas de diálogo entre católicos e metodistas, por meio da Comissão bilateral, iniciaram dois anos após o término do Concílio, em 1967. Portanto, há mais de 40 anos que o Conselho Metodista Mundial e a Igreja Católica Romana vêm fraternalmente travando discussões em torno das possibilidades de conciliação doutrinária e teológica.

Ao longo desse período foram alcançados resultados positivos. Não é

\footnotetext{
${ }^{18}$ A respeito da biografia de José Míguez Bonino, disponível em: <http://www.cogeime.org.br/ faleceu-aos-88-anos-o-teologo-metodista-argentino-dr-jose-miguez-bonino $>$. Acesso em $18 \mathrm{de}$ maio de 2015; e artigo: ÁLVAREZ, Carmelo. "Concilio Vaticano II (1962-1965): una valoración protestante". Disponível em: $<$ http://www.lupaprotestante.com/blog/concilio-vaticano-ii-1962-1965-uma-valoracion-protestante>. Acesso em 18 de maio de 2015.

${ }^{19}$ A experiência das comissões mistas e bilaterais resultam do avanço nas relações ecumênicas não apenas com confissões distintas do cristianismo, sendo também constituídas como meio de diálogo com organismos de representação tais como o Conselho Mundial de Igrejas (CMI). Além do Conselho Metodista Mundial, no âmbito confessional, desde o término do Concílio, pontes de diálogo foram viabilizadas com Ortodoxos, a Federação Luterana Mundial, a Comunhão Anglicana, os Reformados e os Pentecostais.
} 
possível nos parágrafos seguintes discorrer pormenorizadamente sobre os passos dessa caminhada ${ }^{20}$. Serão apenas mencionados relatórios publicados desde os primórdios dessa iniciativa de diálogo, bem como a última iniciativa da Comissão.

Como resultado da primeira fase, em 1971, foi publicado o Relatório de Denver, sublinhando os trabalhos realizados e o valor da herança comum da Igreja Católica Romana e da Igreja Metodista.

$\mathrm{Na}$ segunda fase, sob a égide dos temas "testemunho comum", "espiritualidade", "lar e família cristã"; no ano seguinte (1972), a Comissão publicou o Relatório com esse leque temático pastoral variado. Em 31 de janeiro de 1981, como resultado de discussão iniciada em 1977, publicou o terceiro Relatório versando sobre a pessoa e ação do Espírito Santo. A partir de então a Comissão Mista decidiu pela publicação de cinco em cinco anos dos relatórios dos diálogos.

O quarto Relatório (1982-1986), conhecido como Relatório de Nairobi, exprimiu a preocupação eclesiológica, recebendo o título: "Rumo a uma Declaração sobre a Igreja”. Dedicado à reflexão sobre a Tradição Apostólica, concluiu-se e publicou-se o quinto Relatório (1986-1991). Nas fases que se seguiram foram publicados "A palavra de vida" (1991-1996) e "Dizer a verdade na caridade" (1997-2000), disponível na língua portuguesa. ${ }^{21}$

A última fase do diálogo da Comissão Mista foi a publicação, em 2006, dos estudos sobre eclesiologia "A graça que vos foi dada em Cristo". Nesse mesmo ano o Conselho Mundial Metodista afirmou sua adesão à Declaração Conjunta sobre a Doutrina da Justificação, assinada em 1999 pela Igreja Católica e Federação Luterana Mundial. ${ }^{22}$ Conforme o Monsenhor Donald Bolen afirmou em seu discurso no encontro realizado em Oxford Institute, em 2007: "provavelmente o ano de 2006 foi um dos mais proveitosos para

\footnotetext{
${ }^{20} \mathrm{~A}$ respeito do histórico da relação ecumênica entre católicos e metodistas, cf.: CIPRIANI, Gabriele. "40 anos de diálogo metodista-católico". Disponível em: $<$ http://www.metodista.org. br/40-anos-de-dialogo-metodista-catolico>. Acesso em 18 de maio de 2015.

${ }^{21}$ Comissão Mista: IGREJA CATÓLICA ROMANA e CONSELHO METODISTA MUNDIAL. Dizer a verdade na caridade. A autoridade de ensinar entre católicos e metodistas. São Paulo: Paulinas, 2002.

22 BOLEN, Donald. "Católicos e Metodistas, um diálogo novo". Disponível em: <http:// www.atican.van/roman_curia/pontifical_council/chrstuni/meth-council-docs/rc_pc_chrstuni_ doc_20080121_catholics-methodists_po.html >. Acesso em 18 de maio de 2015. Cf.: Declaração Conjunta sobre a Doutrina da Justificação. Declaração conjunta Católica Romana e Federação Luterana Mundial. $3^{\text {a }}$ ed São Leopoldo: Sinodal; Brasília: CONIC; São Paulo: Paulinas, 2000.
} 
as relações entre católicos e metodistas desde o início oficial do diálogo entre a Igreja Católica e o Conselho Metodista Mundial há quarenta anos". ${ }^{23}$ Momento de aquecido envolvimento da espiritualidade ecumênica no avanço para o diálogo entre as duas Igrejas.

Porém, os reflexos desse avanço no mesmo ano de 2006 não foram acolhidos pela Igreja Metodista no Brasil. Um pouco antes da adesão à Declaração Conjunta, na primeira sessão do XVIII Concílio Geral da Igreja Metodista, decidiu-se pela retirada dos órgãos ecumênicos onde houvesse presença da Igreja Católica Romana, tais como o CONIC, CESE. A ocorrência de tal fato demonstra o risco dos retrocessos, sobretudo quando faltam a compreensão e cultivo da expressão da espiritualidade ecumênica. ${ }^{24}$ Quando o papel mistagógico na transmissão dos conteúdos inspiradores da fé são deixados de lado.

\section{Conclusão}

Caminhar ecumenicamente implica em deixar-se abraçar pela dinâmica envolvente do Espírito. Reivindica a homens e mulheres de boa vontade reencontrar as trilhas do coração para avanços e celebração da comunhão. Procura na partilha dos tesouros espirituais da Igreja de Cristo o que de melhor, concreto e desafiador houver para o aprofundamento das relações agápicas.

Seguindo as direções espirituais que Unitatio Redintegratio oferece, reaviva-se a lembrança de que da mesma forma que uma pipa precisa do vento para alegrar o céu, a Igreja necessita do Espírito da Vida para animá-la a expressar a caridade, realizar uma conversão da alma, sinalizar diaconalmente a pessoa de Cristo e seguir adiante no empenho conjunto para que o mundo creia na justiça e paz do Reino.

\footnotetext{
${ }^{23}$ BOLEN, Donald. "Católicos e Metodistas, um diálogo novo".

${ }^{24}$ Segundo Hélerson Bastos, o envolvimento da Igreja Metodista no Brasil com o movimento e organismos ecumênicos é histórico e fundante. (Cf. RODRIGUES, Hélerson Bastos. No mesmo barco: vivência inter-eclesiástica dos metodistas do Brasil de 1960-1971. São Paulo/São Bernardo do Campo: ASTE/Programa Ecumênico de Pós Graduação em Ciências da Religião (IMS), 1986). Contudo, o "silêncio" em torno do tema, pela liderança e alguns órgãos responsáveis pela comunicação interna, acarretou na apreensão equivocada a respeito do assunto por boa parte dos membros, no que culminou na decisão mencionada da retirada da presença da Igreja Metodista nos órgãos em que houvesse representação Católica Romana (Cf: TUNES, Suzel Magalhães. O pregador silencioso: Ecumenismo no jornal Expositor Cristão (1886-1982). (Dissertação de Mestrado em Ciências da Religião). São Bernardo do Campo: UMESP, 2009).
} 


\section{Referências bibliográficas}

BETTO, Frei; BOFF, Leonardo. Mística e Espiritualidade. $6^{\mathrm{a}}$ ed. Rio de Janeiro: Garamond, 2005.

BOLEN, Donald. "Católicos e Metodistas, um diálogo novo". Disponível em: $<$ http://www.atican.van/roman_curia/pontifical_council/chrstuni/methcouncil-docs/rc_pc_chrstuni_doc_20080121_catholics-methodists po.html>. Acesso em 18 de maio de 2015.

BONINO, José Míguez. Concilio Abierto. Una iterpretación protestante del Concilio Vaticano II. Buenos Aires: La Aurora, 1967.

BONHOEFFER, Dietrich. Vida em comunhão. $5^{\text {a }}$ ed. São Leopoldo: Sinodal, 2003.

BRAKEMEIER, Gottfried. "Preservando a unidade do espirito no vínculo da paz”: um curso de ecumenismo. São Paulo: ASTE, 2004.

CIPRIANI, Gabriele. “40 anos de diálogo metodista-católico”. Disponível em: $<$ http://www.metodista.org.br/40-anos-de-dialogo-metodista-catolico $>$. Acesso em 18 de maio de 2015.

Comissão Mista: IGREJA CATÓLICA ROMANA e CONSELHO METODISTA MUNDIAL. Dizer a verdade na caridade. A autoridade de ensinar entre católicos e metodistas. São Paulo: Paulinas, 2002.

COMPÊNDIO DO VATICANO II. Constituições, Decretos, Declarações. $23^{\mathrm{a}}$ ed. Petrópolis: Vozes, 1994, pp. 307-332.

CONGAR, Yves. Revelação e experiência do Espírito. São Paulo: Paulinas, 2005.

CONIC e CLAI. Diversidade e Comunhão. Um convite ao ecumenismo. $4^{\mathrm{a}} \mathrm{ed}$. São Leopoldo: Sinodal; São Paulo: Paulinas, 2004, pp.13-17.

IECLB e CNBB. Declaração Conjunta sobre a Doutrina da Justificação. Declaração conjunta Católica Romana e Federação Luterana Mundial. $3^{\mathrm{a}}$ ed São Leopoldo: Sinodal; Brasília: CONIC; São Paulo: Paulinas, 2000.

HORTAL, Jesús. E haverá um só rebanho. História, doutrina e prática católica do Ecumenismo. $2^{\mathrm{a}}$ ed. São Paulo: Loyola, 1996.

NOLAN, Albert. Jesus hoje: uma espiritualidade de liberdade radical. São Paulo: Paulinas, 2008. 
PEREIRA, Gerson L. "Luzes da espiritualidade teresiana para o diálogo ecumênico e inter-religioso atual". In: PEDROSA PÁDUA, Lúcia; CAMPOS, Mônica Baptista (Orgs.). Santa Teresa: mística para o nosso tempo. Rio de Janeiro: PUC-Rio/Reflexão, 2011, pp. 203-225.

RIBEIRO, Cláudio; CUNHA, Magali. O Rosto Ecumênico de Deus: reflexões sobre ecumenismo e paz. São Paulo: Fonte Editorial, 2013.

RODRIGUES, Hélerson Bastos. No mesmo barco: vivência inter-eclesiástica dos metodistas do Brasil de 1960-1971. São Paulo/São Bernardo do Campo: ASTE/Programa Ecumênico de Pós-Graduação em Ciências da Religião (IMS), 1986.

TUNES, Suzel Magalhães. O pregador silencioso: Ecumenismo no jornal Expositor Cristão (1886-1982). (Dissertação de Mestrado em Ciências da Religião). São Bernardo do Campo: UMESP, 2009.

VVAA. Sermões de Wesley: Texto em inglês com duas versões em português. São Bernardo do Campo, SP: Editeo, 2006. CD-Rom, Sermão 39.

KASPER, Cardeal Walter. Guia para uma espiritualidade ecumênica. São Paulo: Paulinas, 2007 (Coleção oikoumene).

WOLFF, Elias. "O ecumenismo no horizonte do Concílio Vaticano II". Atualidade Teológica 39 (2011), pp. 403-428.

Gerson Lourenço Pereira

Doutor em Teologia pela Pontifícia Universidade Católica do Rio de Janeiro Professor do Programa de Capacitação Teológica da Igreja Metodista Secretaria de Educação e Cultura do Município de São João de Meriti / RJ

Rio de Janeiro / RJ - Brasil E-mail: gersonlourenco2000@yahoo.com.br

Recebido em: 21/05/15

Aprovado em: 01/03/16 